\title{
Critical Prenatal and Postnatal Periods for Persistent Effects of Dexamethasone on Serotonergic and Dopaminergic Systems
}

\author{
Theodore A Slotkin*,', Marisa L Kreider', Charlotte A Tate' and Frederic J Seidler' \\ 'Department of Pharmacology and Cancer Biology, Duke University Medical Center, Durham, NC, USA
}

\begin{abstract}
Glucocorticoid administration to preterm infants is associated with neurodevelopmental disorders. We treated developing rats with dexamethasone (Dex) at $0.05,0.2$, or $0.8 \mathrm{mg} / \mathrm{kg}$, doses below or spanning the range in clinical use, testing the effects of administration during three different stages: gestational days 17-19, postnatal days 1-3 or postnatal days 7-9. In adulthood, we assessed the impact on synaptic biomarkers for serotonin (5-hydroxytryptamine $(5 \mathrm{HT})$ ) systems. Across all three regimens, Dex administration evoked upregulation of cerebrocortical $5 \mathrm{HT}_{\mathrm{IA}}$ and $5 \mathrm{HT}_{2}$ receptors and the presynaptic $5 \mathrm{HT}$ transporter, greatest for $5 \mathrm{HT}_{\text {IA }}$ receptors. The effects were fully evident even at the lowest dose. In contrast, $5 \mathrm{HT}$ levels in the cerebral cortex and hippocampus showed disparate patterns of temporal sensitivity, with no change after gestational treatment, an increase with the early postnatal regimen, and a decrease with the later postnatal exposure. None of the changes in $5 \mathrm{HT}$ concentrations were offset by adaptive changes in the fractional $5 \mathrm{HT}$ turnover rate. Furthermore, the critical period of sensitivity seen for $5 \mathrm{HT}$ levels differed from that of dopamine even within the same brain region. These findings suggest that developmental exposure to Dex during the critical neurodevelopmental period corresponding to its use in preterm infants, elicits selective changes in $5 \mathrm{HT}$ and dopaminergic synaptic function over and above its effects on general aspects of neural cell development, below the threshold for somatic growth impairment, and even at doses below those used clinically. Accordingly, adverse neurobehavioral consequences may be inescapable in glucocorticoid therapy of preterm infants. Neuropsychopharmacology (2006) 31, 904-9|I. doi:I0.1038/sj.npp. I300892; published online I4 September 2005
\end{abstract}

Keywords: antenatal glucocorticoids; brain development; dexamethasone; dopaminergic systems; preterm delivery; serotonergic systems

\section{INTRODUCTION}

Glucocorticoids are now the consensus treatment for preterm labor occurring between the 24th and 34th weeks of gestation (Gilstrap et al, 1995). These agents, principally dexamethasone (Dex), are now used in nearly one in every ten pregnancies in the US, and consequently, although thousands of preterm infants are spared the adverse consequences of respiratory distress syndrome, hundreds of thousands of infants actually receive treatment (Matthews et al, 2002). Additionally, the use of multiple glucocorticoid courses is common (Crowther and Harding, 2003; Dammann and Matthews, 2001), despite the likelihood of subsequent metabolic, cardiovascular and behavioral anomalies (Barrington, 2001; Seckl, 2001; Shinwell et al, 2000; Trautman et al, 1995; Yeh et al, 2004). Recent reviews point out the long-term consequences of the use of

*Correspondence: Dr TA Slotkin, Department of Pharmacology and Cancer Biology, Duke University Medical Center, Box 38 I3 DUMC, Room CI62, LSRC Building, Research Drive, Durham, NC 27710, USA, Tel: + | 919 681 8015, Fax: + | 9196848197 ,

E-mail: t.slotkin@duke.edu

Received 16 May 2005; revised 5 July 2005; accepted 5 August 2005 Online publication: 5 August 2005 at http://www.acnp.org/citations/ Npp080505050327/default.pdf antenatal steroids (Blackmon et al, 2002; Coe and Lubach, 2005; Newnham, 2001; Raff, 2004; Seckl, 2004) but isolating an explicit glucocorticoid effect in human populations is confounded by the comorbidities and interventions that are characteristic of preterm labor; as just one example, terbutaline, which is typically given to arrest uterine contractions (Lam et al, 1998) is itself a developmental neurotoxicant (Rhodes et al, 2004; Slotkin et al, 2003).

Accordingly, there is a critical need for animal studies specifically designed to assess the consequences of glucocorticoids used within the developmental context of preterm labor. Heretofore, most reports have focused on treatments that produce persistent stunting of somatic growth, outright cerebral atrophy and endocrine disruption (Bohn, 1984; Fuxe et al, 1994, 1996; Gilad et al, 1998; Gould et al, 1997; Maccari et al, 2003; Matthews, 2000; Matthews et al, 2002; McEwen, 1992; Meaney et al, 1996; Weinstock, 2001; Welberg and Seckl, 2001). To bridge the gap, we recently performed studies in developing rats, showing that Dex treatment, even at doses that lie below those used in the therapy of preterm delivery and that do not compromise long-term somatic growth, nevertheless disrupts neural cell acquisition, indices of neuritic outgrowth, synaptic activity and cell signaling involved in trophic regulation of forebrain development (Kreider et al, 2005a). These effects 
were associated with long-term changes in cognition and motor activity (Kreider et al, 2005b), resembling those seen in models of prenatal stress (Bowman et al, 2004; Dean et al, 2001; Felszeghy et al, 2000; Muneoka et al, 1997). Interestingly, the persistent effects on cholinergic synaptic function showed regional selectivity and critical periods of vulnerability that differed from the general effects on neural cell acquisition and development (Kreider et al, 2006). Indeed, indices of synaptic function were disrupted far more extensively than general architectural biomarkers, representing interference with the functioning of a variety of cholinergic and noncholinergic G-protein-coupled receptors, superimposed on presynaptic hyperactivity. These findings suggest that morphological evaluations of the consequences of developmental exposure to Dex (Bohn, 1984) grossly underestimate the vulnerability of the developing brain and that the misprogramming of synaptic function may represent one of the major targets responsible for neurobehavioral anomalies.

In the current study, we evaluated the targeting of serotonergic (5-hydroxytryptamine (5HT)) systems. In the adult, glucocorticoids play a key role in the regulation of $5 \mathrm{HT}$ receptor expression and synaptic function, contributing to many of the attributes of affective disorders (Aghajanian et al, 1993; Young, 1994) and therefore we hypothesized that 5HT pathways were a likely target for anomalous programming of synaptic function consequent to prenatal or early neonatal Dex treatment. We administered Dex to rats during defined perinatal periods corresponding to phases of human neurodevelopment in the second to early third trimester, the period which glucocorticoids are most likely to be used in preterm infants (Dobbing and Sands, 1979; Gilstrap et al, 1995; Kreider et al, 2005a, 2006; Rodier, 1988): gestational days (GD) 17-19, postnatal days (PN) 1-3 and PN7-9. For each regimen, we examined doses below $(0.05 \mathrm{mg} / \mathrm{kg})$ or within the therapeutic range $(0.2$ or $0.8 \mathrm{mg} / \mathrm{kg})$, a strategy adopted from our earlier work on architectural and cholinergic biomarkers (Kreider et al, 2005a, 2006), and focused on the cerebral cortex and hippocampus, the regions displaying the largest and most persistent effects on architectural, cholinergic and synaptic signaling indices (Kreider et al, 2006). In addition, a number of studies point to sexually dimorphic neurochemical and behavioral effects of developmental glucocorticoid exposure (Bowman et al, 2004; Gerardin et al, 2005; Kreider et al, 2005a, b, 2006; Rieger et al, 2004), so we contrasted the long-term effects in males and females.

Our assessments focused on expression of the presynaptic $5 \mathrm{HT}$ transporter, which is responsible for regulating the concentration of 5HT in the synapse (Cooper et al, 1996) and two $5 \mathrm{HT}$ receptor subtypes, $5 \mathrm{HT}_{1 \mathrm{~A}}$ and $5 \mathrm{HT}_{2}$, that are known to be affected in human depression (Arango et al, 2001; Fujita et al, 2000; Yatham et al, 1999, 2000). In addition, we evaluated 5HT levels and turnover. The latter is an index of presynaptic neuronal activity (Slotkin et al, 2000; Xu et al, 2001) and was assessed using the metabolite ratio, that is, the proportion of 5-hydroxyindoleacetic acid (5HIAA) to 5HT. Finally, we contrasted the effects on 5HT levels and turnover with those for dopamine (DA), in order to determine whether different types of synapses within the same brain region can undergo separable programming of activity by developmental Dex exposure. DA and its metabolites, dihydroxyphenylacetic acid (DOPAC) and homovanillic acid (HVA), were evaluated and again, the turnover was calculated by the metabolite ratio method (Slotkin et al, 2000; Xu et al, 2001).

\section{METHODS}

\section{Animal Treatments}

All studies were performed in accordance with the Declaration of Helsinki and with the Guide for the Care and Use of Laboratory Animals as adopted and promulgated by the National Institutes of Health. Timed-pregnant Sprague-Dawley rats (Charles River, Raleigh, NC) were housed individually and given free access to food and water. For studies of gestational Dex exposure, dams received daily subcutaneous injections of Dex phosphate (Sigma Chemical Co., St Louis, MO) at doses of $0.05,0.2$, or $0.8 \mathrm{mg} / \mathrm{kg}$ on GD17-19, whereas controls received equivalent volumes $(1 \mathrm{ml} / \mathrm{kg})$ of isotonic saline vehicle. On the day after birth, all pups were randomized within their respective treatment groups and redistributed to the nursing dams, maintaining a litter size of 10 to ensure standard nutrition. Randomization was repeated every 3-4 days and in addition, dams were rotated among litters to obviate any differences in maternal caretaking. Crossfostering does not alter the developmental effects of Dex, nor does fostering of normal pups by Dex-treated dams produce apparent treatment effects in controls (Nyirenda et al, 2001). For studies of the effects of postnatal Dex treatment, pups were given 0 , $0.05,0.2$, or $0.8 \mathrm{mg} / \mathrm{kg}$ on PN1-3 or PN7-9 and the same randomization procedures were followed. Animals were weaned on PN21.

On PN60, animals were decapitated, the cerebellum was removed and the forebrain was separated from the brainstem by a cut rostral to the thalamus, after which the hippocampus was dissected and the striatum was removed to leave the cerebral cortex as the remainder, which was then divided down the midline to give separate samples of left and right cortex. Brain regions were frozen in liquid nitrogen and stored at $-45^{\circ} \mathrm{C}$. Each treatment group consisted of six males and six females, with each animal derived from a different litter.

\section{HT Receptors and Transporter}

The samples of the left cerebral cortex were thawed and homogenized (Polytron, Brinkmann Instruments, Westbury, NY) in ice-cold $50 \mathrm{mM}$ Tris ( $\mathrm{pH} 7.4$ ), and the homogenates were sedimented at $40000 \mathrm{~g}$ for $15 \mathrm{~min}$. The pellets were washed by resuspension (Polytron) in homogenization buffer followed by resedimentation, and were then dispersed with a homogenizer (smooth glass fitted with Teflon pestle) in the same buffer. Two radioligands (PerkinElmer Life Sciences, Boston, MA) were used to determine 5HT receptor binding (Aldridge et al, 2003, 2004): $1 \mathrm{nM} \mathrm{[}{ }^{3} \mathrm{H}$ ] 8-hydroxy-2-(di- $n$-propylamino)tetralin (specific activity, $135 \mathrm{Ci} / \mathrm{mmol}$ ) for $5 \mathrm{HT}_{1 \mathrm{~A}}$ receptors, and $0.4 \mathrm{nM}\left[{ }^{3} \mathrm{H}\right]$ ketanserin (specific activity, $63 \mathrm{Ci} / \mathrm{mmol}$ ) for $5 \mathrm{HT}_{2}$ receptors. For $5 \mathrm{HT}_{1 \mathrm{~A}}$ receptors, incubations lasted for $30 \mathrm{~min}$ at $25^{\circ} \mathrm{C}$ in a buffer consisting of $50 \mathrm{mM}$ Tris ( $\mathrm{pH} \mathrm{8),}$ $0.5 \mathrm{mM} \mathrm{MgCl}_{2}$ and $0.5 \mathrm{mM}$ sodium ascorbate; $100 \mu \mathrm{M} 5 \mathrm{HT}$ 
(Sigma) was used to displace specific binding. For $5 \mathrm{HT}_{2}$ receptors, incubations lasted $15 \mathrm{~min}$ at $37^{\circ} \mathrm{C}$ in $50 \mathrm{mM}$ Tris $(\mathrm{pH}$ 7.4) and specific binding was displaced with $10 \mu \mathrm{M}$ methylsergide (Sandoz Pharmaceuticals, E. Hanover, NJ). Incubations were stopped by the addition of excess of icecold incubation buffer (without radioligand or displacing agent) and the labeled membranes were trapped by rapid vacuum filtration onto glass fiber filters that were presoaked in $0.15 \%$ polyethyleneimine. The filters were then washed twice with $3 \mathrm{ml}$ of incubation buffer and radiolabel was determined. For binding to the presynaptic 5HT transporter (Aldridge et al, 2003, 2004), the membrane suspension was incubated in a buffer consisting of $50 \mathrm{mM}$ Tris ( $\mathrm{pH} 7.4$ ), $120 \mathrm{mM} \mathrm{NaCl}$, and $5 \mathrm{mM} \mathrm{KCl}$, with addition of $85 \mathrm{pM}\left[{ }^{3} \mathrm{H}\right]$ paroxetine (specific activity $19.4 \mathrm{Ci} / \mathrm{mmol}$; PerkinElmer) with or without $100 \mu \mathrm{M} 5 \mathrm{HT}$ to displace specific binding. Incubations lasted $120 \mathrm{~min}$ at $20^{\circ} \mathrm{C}$.

\section{HT and DA Levels and Turnover}

The samples of the right cerebral cortex and the hippocampus were thawed and homogenized in ice-cold $0.1 \mathrm{M}$ perchloric acid and sedimented for $20 \mathrm{~min}$ at $40000 \mathrm{~g}$. The supernatant solution was collected and aliquots were used for analysis of 5HT, 5HIAA, DA, HVA and DOPAC by HPLC with electrochemical detection (Slotkin et al, 2000; Xu et al, 2001). Concurrently run standards, containing each of the neurotransmitters and metabolites (Sigma), were used to calculate the regional concentration of each neurochemical. DOPAC and HVA levels in the hippocampus were too low for accurate measurement, so only 5HT levels and turnover are reported for that region. Turnover values for $5 \mathrm{HT}$ and DA systems were then determined as the ratio of metabolites to the native neurotransmitter: 5HIAA/5HT and (DOPAC + HVA)/DA, respectively.

\section{Data Analysis}

Data are presented as means and SE. Differences between groups were first assessed by a global analysis of variance
(ANOVA) (data log-transformed because of heterogeneous variance), incorporating all factors: treatment regimen, dose, sex, and, for the ligand binding studies, the multiple measurements made from each membrane preparation $\left(5 \mathrm{HT}_{1 \mathrm{~A}}\right.$ and $5 \mathrm{HT}_{2}$ receptors, $5 \mathrm{HT}$ transporter), which were then regarded as repeated measures. Since 5HT levels and turnover were assessed in cerebral cortex and hippocampus, we included the additional factor of region in the initial ANOVA. Depending upon the treatment interactions obtained in the global tests, data were then subdivided for lower order ANOVAs, followed where appropriate, by Fisher's Protected Least Significant Difference to establish effects comparing individual groups. However, in the absence of interactions of treatment with other variables, only the main effects are reported without lower-order tests. Significance was assumed at $p<0.05$. For convenience, some data are presented as the percentage change from control values; however, statistical evaluations were always carried out on the original data. For reference, control values appear in Table 1, compiled across all three control cohorts (those receiving vehicle injections on GD17-19, PN1-3, or PN7-9); however, the effects of Dex were determined only against the appropriately matched control cohort.

\section{RESULTS}

In control animals, there were only two significant sex differences among all the parameters measured (Table 1). Females displayed higher values for 5HT transporter binding in the cerebral cortex and for 5HT turnover in the hippocampus. In keeping with earlier findings with these Dex regimens (Kreider et al, 2005b, 2006), animals receiving doses of 0.05 or $0.2 \mathrm{mg} / \mathrm{kg}$ did not display somatic growth impairment in adulthood, whereas those given the highest dose had body weights that were about $10 \%$ below normal, with the group exposed on PN7-9 showing a statistically significant reduction $(p<0.002$, not shown). There were no significant effects on brain region weights (not shown).

Table I Control Values

\begin{tabular}{|c|c|c|c|c|}
\hline \multirow[b]{2}{*}{ Measure } & \multicolumn{2}{|c|}{ Cerebral cortex } & \multicolumn{2}{|c|}{ Hippocampus } \\
\hline & Male & Female & Male & Female \\
\hline $5 \mathrm{HT}_{2}$ receptor binding (fmol/mg protein) & $101 \pm 3$ & $99 \pm 2$ & & \\
\hline 5HT transporter binding (fmol/mg protein) & $367 \pm 7$ & $393 \pm 5^{a}$ & & \\
\hline $5 \mathrm{HT}$ fractional turnover & $0.83 \pm 0.08$ & $0.85 \pm 0.06$ & $1.19 \pm 0.08$ & $1.50 \pm 0.10^{2}$ \\
\hline DA concentration (ng/g tissue) & $525 \pm 25$ & $511 \pm 19$ & & \\
\hline DOPAC concentration (ng/g tissue) & $10 \mid \pm 3$ & $105 \pm 3$ & & \\
\hline HVA concentration (ng/g tissue) & $59 \pm 2$ & $67 \pm 3$ & & \\
\hline DA fractional turnover & $0.30 \pm 0.01$ & $0.33 \pm 0.01$ & & \\
\hline
\end{tabular}

Values were compiled from all three control cohorts: those receiving saline injections on GDI7-19, PNI-3, or PN7-9.

${ }^{a}$ Significant difference between males and females. 
a

$5 \mathrm{HT}_{1 \mathrm{~A}}$ Receptor Binding - Cerebral Cortex

ANOVA: Treatment, $p<0.0002$

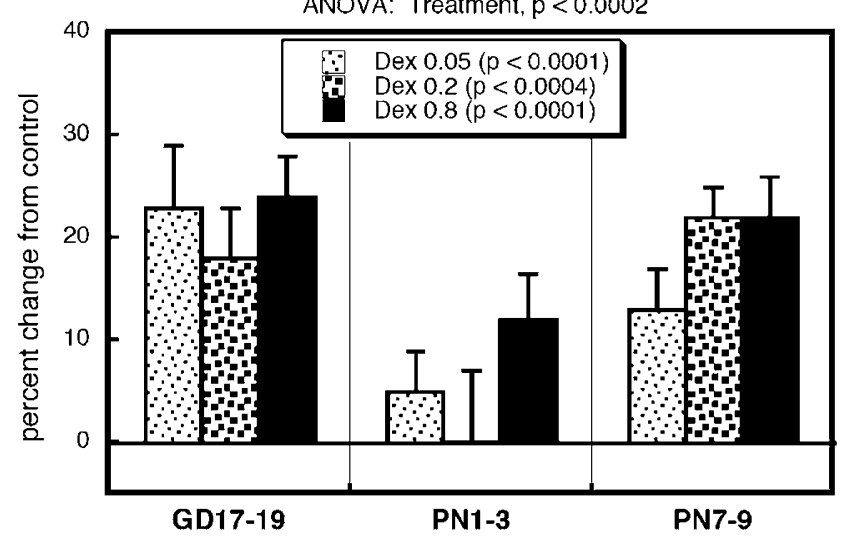

b $\quad 5 \mathrm{HT}_{2}$ Receptor Binding - Cerebral Cortex

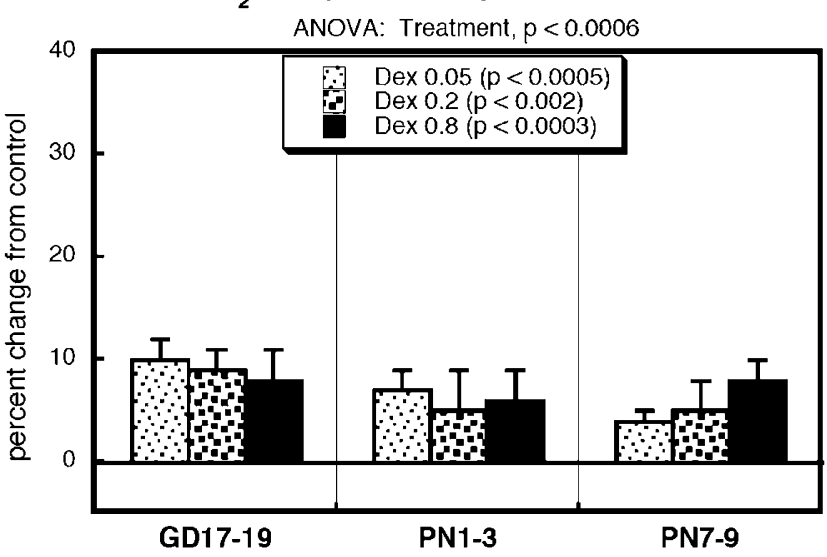

C 5HT Transporter Binding - Cerebral Cortex
ANOVA: Treatment, $p<0.0001$

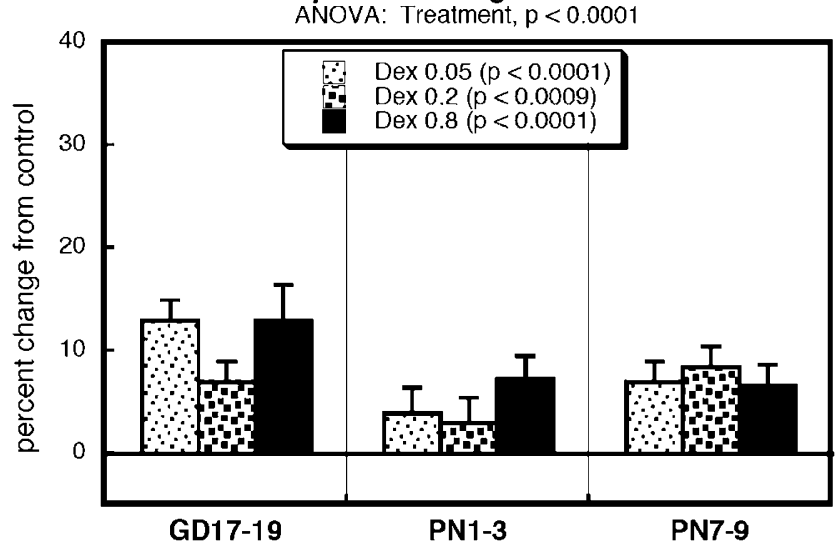

Figure I Effects of Dex regimens on ligand binding to $5 \mathrm{HT} \mathrm{T}_{\mathrm{A}}$ receptors (a) $5 \mathrm{HT}_{2}$ receptors (b) and the $5 \mathrm{HT}$ transporter (c), evaluated on PN60 and presented as the percent change from control values shown in Table I. Across all regimens, doses, both sexes and all three measures, ANOVA identified a main treatment effect $(p<0.000 \mathrm{I})$ and an interaction of treatment $\times$ measure $(p<0.02)$. Accordingly, values were separated into the three individual measures and ANOVA is shown at the top of each panel, and main effects for each dose are given within the panels. Lower-order analyses for each regimen or region were not carried out because of the absence of treatment interactions with these variables; similarly, effects on males and females were combined because of the absence of treatment $x$ sex interactions.

Despite the limited effects of these Dex treatments on somatic growth, effects on 5HT and DA systems were detectable for all three regimens and even at the lowest Dex a 5HT Concentration

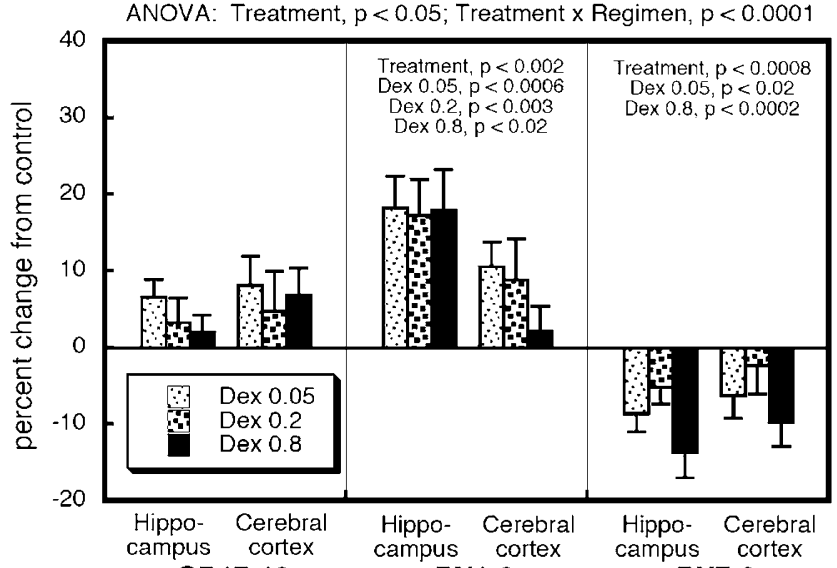

GD17-19

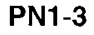

PN7-9

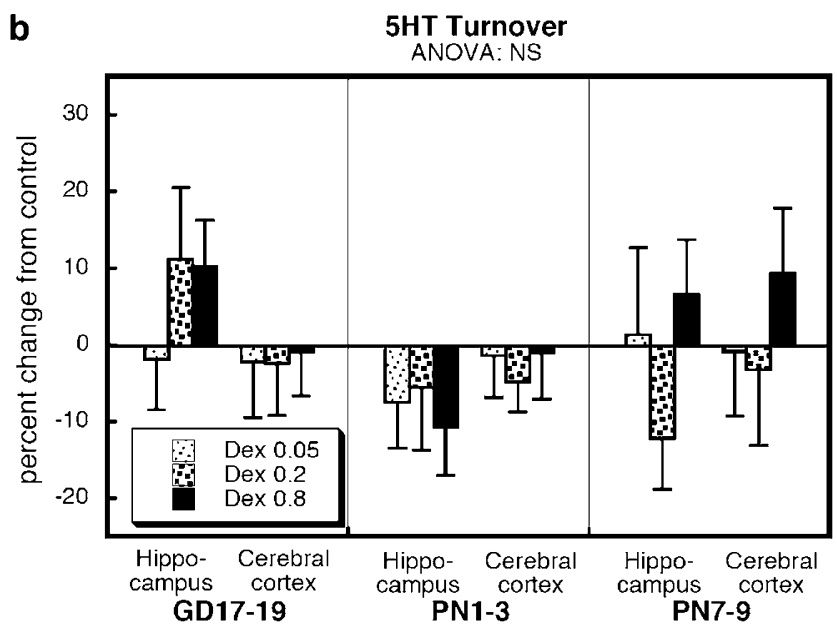

Figure 2 Effects of Dex regimens on $5 \mathrm{HT}$ levels (a) and fractional turnover (b), evaluated on PN60 and presented as the percent change from control values shown in Table I. ANOVA across all regimens, doses and both sexes is shown at the top of each panel, and, because of the interaction of treatment $\times$ regimen in (a), lower-order ANOVAs for each regimen appear within the panel. Separate analyses for each region were not carried out because of the absence of treatment $x$ region interactions and effects on males and females were combined because of the absence of treatment $\times$ sex interactions. NS, not significant.

dose. For ligand-binding parameters, there were robust overall treatment effects $(p<0.0001)$, with selectively greater effects on $5 \mathrm{HT}_{1 \mathrm{~A}}$ receptors (treatment $\times$ measure, $p<0.02$ ), although significant differences were found for all three sites. Elevations of $5 \mathrm{HT}_{1 \mathrm{~A}}$ receptor binding ranged as high as $25 \%$ above control values and were readily demonstrable even at $0.05 \mathrm{mg} / \mathrm{kg}$ of Dex (Figure 1a). In contrast, $5 \mathrm{HT}_{2}$ receptors displayed increases of no more than $10 \%$ although these, too, were statistically significant (Figure 1b). Results for the 5HT transporter resembled those for $5 \mathrm{HT}_{2}$ receptors, with small, but significant overall elevations at all doses across all regimens (Figure 1c). In addition, the highest dose of Dex had a somewhat greater effect on transporter binding in males than females (13vs $5 \%$ elevation), which effectively eliminated the normal sex difference in this parameter.

Dex treatment also elicited increases in 5HT levels, although in this case, there were disparities among the 

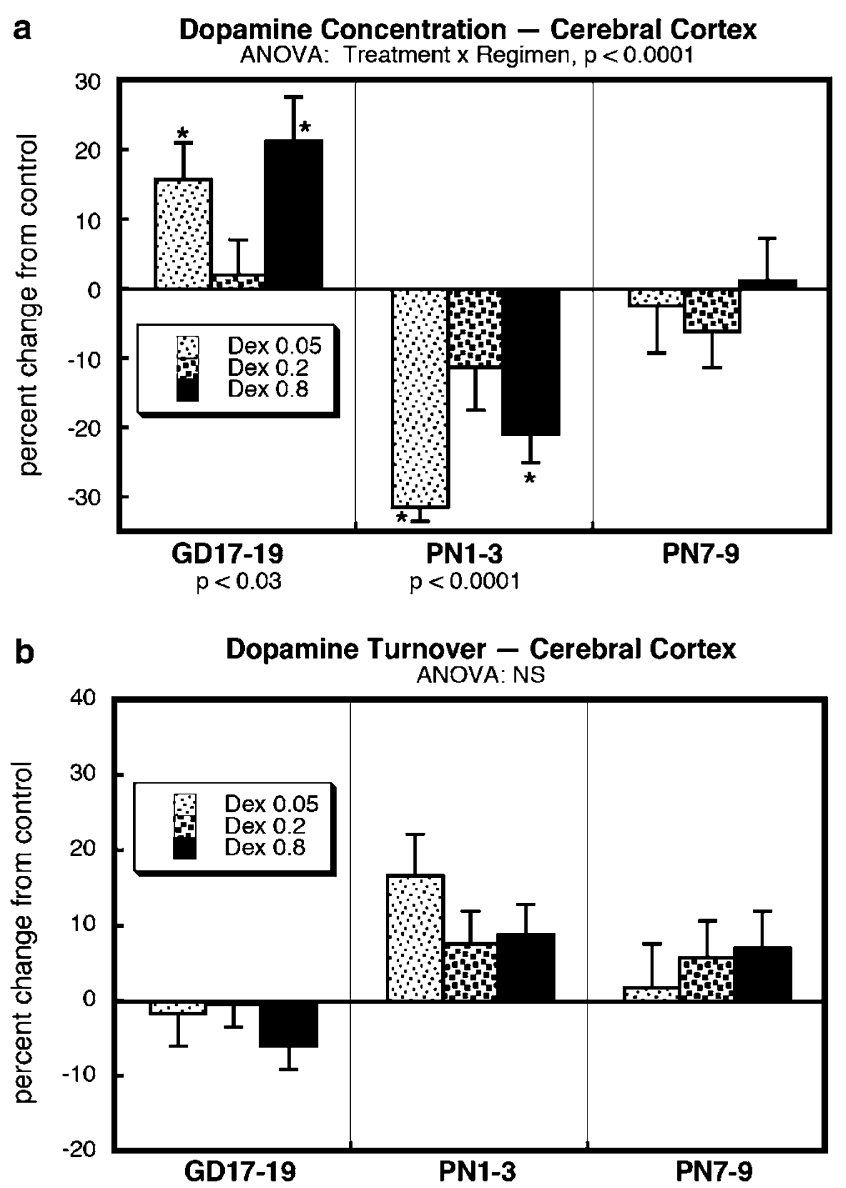

Figure 3 Effects of Dex regimens on cerebrocortical DA levels (a) and fractional turnover (b), evaluated on PN60 and presented as the percent change from control values shown in Table I. ANOVA across all regimens, doses and both sexes is shown at the top of each panel, and, because of the interaction of treatment $\times$ regimen in (a), lower-order ANOVAs for each regimen appear below the panel; asterisks indicate individual treatment effects that differ from the corresponding control. Effects on males and females were combined because of the absence of treatment $\times$ sex interactions. NS, not significant.

three different regimens (Figure 2a). Treatment on GD17-19 did not produce significant alterations but shifting the exposure period to PN1-3 evoked increases of $10-20 \%$, again displaying significance even at a dose of $0.05 \mathrm{mg} / \mathrm{kg}$. When given later in the postnatal period (PN7-9), Dex instead produced significant decrements in the 5HT level. Despite the changes in 5HT levels, there were no significant differences in the fractional turnover of 5HT (Figure 2b). Furthermore, Dex treatment did not reverse the sex differences in hippocampal 5HT turnover that had been seen in the control group (Table 1): sex differences were significant for all Dex doses $(p<0.05$ for Dex $0.05 \mathrm{mg} / \mathrm{kg}$, $p<0.02$ for Dex $0.2 \mathrm{mg} / \mathrm{kg}, p<0.05$ for Dex $0.8 \mathrm{mg} / \mathrm{kg}$ ).

For cerebrocortical DA levels, Dex treatment had even greater effects and displayed an earlier period of vulnerability. Treatment on GD17-19 evoked elevations of up to $20 \%$ whereas the PN1-3 regimen produced even more robust decreases (Figure 3a). By PN7-9, Dex treatment no longer showed significant long-term alterations in DA levels, indicating closure of the critical period of vulner- ability for this transmitter. Just as was true for 5HT, DA turnover was unaffected despite the large changes in transmitter levels (Figure $3 \mathrm{~b}$ ).

\section{DISCUSSION}

The key findings of this study are that: (1) Dex administration produces lasting alterations in indices of 5HT and DA synaptic signaling even at doses below those used therapeutically in preterm infants and in the absence of somatic growth inhibition; (2) the global upregulation of 5 HT synaptic proteins occurs independently of changes in 5HT levels or turnover; and (3) the critical periods of vulnerability to Dex differ between transmitter systems even within the same brain region, implying that there is specific targeting of neurons according to their phenotype, rather than simply a generalized disruption of neural cell development. In an earlier study (Kreider et al, 2006), we found that deficits in cerebrocortical cell numbers were far more profound with Dex treatment on PN7-9, whereas in the current work, 5HT synaptic proteins showed a much wider window of susceptibility, with significant effects across all regimens and, if anything, slightly greater effects with GD17-19 Dex treatment. Similarly, as found earlier, effects on cholinergic synaptic activity appear to be maximal with gestational exposure rather than the PN7-9 regimen (Kreider et al, 2006), in keeping with the concept that the effects of Dex on specific neurotransmitter pathways is separable from those on biomarkers that reflect overall architectural features.

Indeed, the effects on 5HT levels and turnover not only reinforce this idea but also provide mechanistic insight into the effects underlying the upregulation of 5HT synaptic proteins. Unlike the global increase in the protein markers, 5HT levels showed disparate temporal effects, with no change after Dex treatment on GD17-19, an increase with the PN1-3 regimen, and a decrease after the PN7-9 exposure. In no case did we observe a change in the fractional turnover of 5HT; consequently, the changes in $5 \mathrm{HT}$ level are uncorrected by corresponding alterations in impulse activity and thus are likely to dictate a corresponding change in the concentration of 5HT in the synapse. Accordingly, a decrease in transmitter level without a compensatory increase in fractional turnover means a decrease in presynaptic function, whereas an increase in level without a decrease in turnover implies an increase in function. Viewed in that light, the increase in 5HT levels seen with the PN1-3 Dex treatment may be one of the reasons why the upregulation of 5HT receptors is smallest among the three regimens: increased synaptic 5HT concentrations foster receptor downregulation, partially offsetting the primary upregulation caused by Dex.

Nevertheless, it is apparent that alterations of presynaptic activity are not the sole driving force behind the effects of Dex on 5HT receptors or expression of the 5HT transporter, since upregulation was seen regardless of whether 5HT levels were unchanged (GD17-19), increased (PN1-3) or decreased (PN7-9); indeed, increases in receptors in the face of a rise in presynaptic 5HT may seem particularly puzzling, since ordinarily one would expect to see compensatory downregulation. In fact, the disconnection provides im- 
portant clues as to the mechanisms underlying the effects of Dex on 5HT function. A pattern of global upregulation of synaptic proteins in the face of increased presynaptic activity has been seen with other neuroteratogens unrelated to glucocorticoids and typically reflects either a loss of postreceptor-signaling capabilities (Shahak et al, 2003; Yanai et al, 2004) or architectural 'miswiring,' where neural projections do not connect to the proper postsynaptic cells (Aldridge et al, 2005b; Steingart et al, 1998; Vatury et al, 2004). In either situation, the failure of synaptic signals to activate postsynaptic signaling leads to both an increase in presynaptic activity and upregulation of synaptic proteins in an unsuccessful attempt to compensate for the underlying deficiency. In the present case, there is already significant information supporting the loss of postreceptor coupling (Kreider et al, 2006), but certainly, miswiring may also participate in the net effects. In fact, the greater damage to architectural markers with the PN7-9 regimen (Kreider et al, 2006) may contribute to the decrements in $5 \mathrm{HT}$ levels seen with this treatment, superimposed on more direct effects of Dex on 5HT systems. This biphasic relationship, a promotional effect that is offset as neural cell loss or damage intensifies, is typical for effects of Dex on brain development (Kreider et al, 2005a, 2006; Slotkin et al, 1991; Zahalka et al, 1993).

Our findings for DA further support the idea of selective effects of Dex on different transmitter systems. DA levels were increased with the GD17-19 regimen but decreased after exposure on PN1-3, a temporal pattern resembling that seen with $5 \mathrm{HT}$, but shifted to much earlier in development. Accordingly, the temporal transition from promotional to inhibitory effects is distinct for DA and $5 \mathrm{HT}$, even within the same brain region. Furthermore, as was true for 5HT, the effects on DA levels were unaccompanied by significant changes in fractional turnover, so that the increases or decreases in levels dictate corresponding changes in DA concentrations within the synapse. This conclusion is further supported by the existence of disparate temporal patterns for effects on cholinergic and noradrenergic systems as reported previously (Kreider et al, 2006; Slotkin et al, 1992). Indeed, for the latter two transmitters, as well as for effects on cell-signaling downstream from the receptors, we found strongly sex-selective effects that served to eliminate normal sex differences between males and females (Kreider et al, 2005b, 2006). Although in the present study, we did find that Dex treatment eliminated the sex differences in 5HT transporter expression, it did not obtund those for transmitter turnover, so that these effects, too, appear to be transmitter selective.

The dysregulation of 5HT and DA synaptic activity in adulthood clearly contributes to the adverse behavioral outcomes noted for perinatal glucocorticoid treatments, which include persistent abnormalities of hypothalamuspituitary-adrenal (HPA) axis function and stress responses as well as cognitive impairment (Kreider et al, 2005b; Matthews, 2000; Matthews et al, 2002; McEwen, 1992; Meaney et al, 1996; Welberg and Seckl, 2001). Both 5HT and DA play important roles in the setpoint for HPA reactivity (Korte et al, 1991; Stokes et al, 1987) and glucococorticoids in turn regulate the expression and function of the receptors for these two transmitters (Aghajanian et al, 1993; Young, 1994). It would therefore be worthwhile to investigate the extent to which early glucocorticoid exposure elicits persistent changes in HPA responses through its effects on 5HT and DA systems, or whether these animals display behavioral anomalies akin to those found in animal models of depression that involve deficient monoamine function (Jesberger and Richardson, 1985; Kelly et al, 1997; Song, 2000). One potential strategy is to use selective receptor antagonists to isolate the participation of specific 5HT and DA inputs in the functional outcomes (Aldridge et al, 2005a).

In conclusion, our results indicate that Dex administration during phases of brain development akin to those in preterm infants, produces persistent changes in indices of 5HT and DA synaptic function. Of critical importance, the effects are exerted even at doses well below those used therapeutically and are dissociated from impaired somatic growth or architectural disruption of brain development. Further, the specific involvement of cerebrocortical 5HT and DA systems means that more attention may need to be directed toward potential effects on mood, anxiety, appetitive and sleep disorders, or on reward function (Aghajanian et al, 1993; Nemeroff, 1998), as distinct from the past emphasis on hippocampal cholinergic systems and cognitive performance, or on hypothalamic systems and stress responses. The effects of Dex seen here strongly suggest that, within the context of its use in preterm infants (Gilstrap et al, 1995), adverse neurobehavioral consequences are inescapable.

\section{REFERENCES}

Aghajanian GK, Charney DS, Duman RS, Heninger GR (1993). Neurobiology of Affective Disorders. Raven Press: New York.

Aldridge JE, Levin ED, Seidler FJ, Slotkin TA (2005a). Developmental exposure of rats to chlorpyrifos leads to behavioral alterations in adulthood, involving serotonergic mechanisms and resembling animal models of depression. Environ Health Perspect 113: 527-531.

Aldridge JE, Meyer A, Seidler FJ, Slotkin TA (2005b). Alterations in central nervous system serotonergic and dopaminergic synaptic activity in adulthood after prenatal or neonatal chlorpyrifos exposure. Environ Health Perspect 113: 1027-1031.

Aldridge JE, Seidler FJ, Meyer A, Thillai I, Slotkin TA (2003). Serotonergic systems targeted by developmental exposure to chlorpyrifos: effects during different critical periods. Environ Health Perspect 111: 1736-1743.

Aldridge JE, Seidler FJ, Slotkin TA (2004). Developmental exposure to chlorpyrifos elicits sex-selective alterations of serotonergic synaptic function in adulthood: critical periods and regional selectivity for effects on the serotonin transporter, receptor subtypes, and cell signaling. Environ Health Perspect 112: $148-155$.

Arango V, Underwood MD, Boldrini M, Tamir H, Kassir SA, Hsiung $S$ et al (2001). Serotonin-1A receptors, serotonin transporter binding and serotonin transporter mRNA expression in the brainstem of depressed suicide victims. Neuropsychopharmacology 25: 892-903.

Barrington KJ (2001). The adverse neuro-developmental effects of postnatal steroids in the preterm infant: a systematic review of RCTs. BMC Pediatr 1: 1-9.

Blackmon LR, Bell EF, Engle WA, Kanto WP, Martin GI, Miller CA et al (2002). Postnatal corticosteroids to treat or prevent chronic lung disease in preterm infants. Pediatrics 109: 330-338. 
Bohn MC (1984). Glucocorticoid induced teratologies of the nervous system. In: Yanai J (eds). Neurobehavioral Teratology. Elsevier: Amsterdam. pp 365-387.

Bowman RE, MacLusky NJ, Sarmiento Y, Frankfurt M, Gordon M, Luine VN (2004). Sexually dimorphic effects of prenatal stress on cognition, hormonal responses, and central neurotransmitters. Endocrinology 145: 3778-3787.

Coe CL, Lubach GR (2005). Developmental consequences of antenatal dexamethasone treatment in nonhuman primates. Neurosci Biobehav Rev 29: 227-235.

Cooper JR, Bloom FE, Roth RH (1996). The Biochemical Basis of Neuropharmacology, 7th edn. Oxford University Press: New York, 518pp.

Crowther CA, Harding J (2003). Repeat doses of prenatal corticosteroids for women at risk of preterm birth for preventing neonatal respiratory disease. Cochrane Database Systemat Rev 1: CD003935.

Dammann O, Matthews SG (2001). Repeated antenatal glucocorticoid exposure and the developing brain. Pediatr Res 50: 563-564.

Dean F, Yu C, Lingas RI, Matthews SG (2001). Prenatal glucocorticoid modifies hypothalamo-pituitary-adrenal regulation in prepubertal guinea pigs. Neuroendocrinology 73: 194-202.

Dobbing J, Sands J (1979). Comparative aspects of the brain growth spurt. Early Human Dev 3: 79-83.

Felszeghy K, Bagdy G, Nyakas C (2000). Blunted pituitaryadrenocortical stress response in adult rats following neonatal dexamethasone treatment. J Neuroendocrinol 12: 1014-1021

Fujita M, Charney DS, Innis RB (2000). Imaging serotonergic neurotransmission in depression: hippocampal pathophysiology may mirror global brain alterations. Biol Psychiatr 48: 801-812.

Fuxe K, Cintra A, Chadi G, Gustafsson JÅ, Agnati LF (1994). Central glucocorticoid receptors and neuronal plasticity. Meth Neurosci 22: 372-382.

Fuxe K, Diaz R, Cintra A, Bhatnagar M, Tinner B, Gustafsson JA et al (1996). On the role of glucocorticoid receptors in brain plasticity. Cell Mol Neurobiol 16: 239-258.

Gerardin DC, Pereira OC, Kempinas WG, Florio JC, Moreira EG, Bernardi MM (2005). Sexual behavior, neuroendocrine, and neurochemical aspects in male rats exposed prenatally to stress. Physiol Behav 84: 97-104.

Gilad GM, Gilad VH, Eliyayev Y, Rabey JM (1998). Developmental regulation of the brain polyamine-stress-response. Int J Dev Neurosci 16: 271-278.

Gilstrap LC, Christensen R, Clewell WH, D'Alton ME, Davidson EC, Escobedo MB et al (1995). Effect of corticosteroids for fetal maturation on perinatal outcomes. J Am Med Assoc 273: 413-418.

Gould E, Tanapat P, McEwen BS (1997). Activation of the type 2 adrenal steroid receptor can rescue granule cells from death during development. Dev Brain Res 101: 265-268.

Jesberger JA, Richardson JS (1985). Animal models of depression: parallels and correlates to severe depression in humans. Biol Psychiatr 20: 764-784.

Kelly JP, Wrynn AS, Leonard BE (1997). The olfactory bulbectomized rat as a model of depression: an update. Pharmacol Ther 74: 299-316.

Korte SM, Van Duin S, Bouws GAH, Koolhaas JM, Bohus B (1991). Involvement of hypothalamic serotonin in activation of the sympathoadrenalmedullary system and hypothalamo-pituitaryadrenocortical axis in male Wistar rats. Eur J Pharmacol 197: 225-228.

Kreider ML, Aldridge JE, Cousins MM, Oliver CA, Seidler FJ, Slotkin TA (2005a). Disruption of rat forebrain development by glucocorticoids: critical perinatal periods for effects on neural cell acquisition and on cell signaling cascades mediating noradrenergic and cholinergic neurotransmitter/neurotrophic responses. Neuropsychopharmacology 30: 1841-1855.

Kreider ML, Levin ED, Seidler FJ, Slotkin TA (2005b). Gestational dexamethasone treatment elicits sex-dependent alterations in locomotor activity, reward-based memory and hippocampal cholinergic function in adolescent and adult rats. Neuropsychopharmacology 30: 1617-1623.

Kreider ML, Tate CA, Cousins MM, Oliver CA, Seidler FJ, Slotkin TA (2006). Lasting effects of developmental dexamethasone treatment on neural cell number and size, synaptic activity and cell signaling: critical periods of vulnerability, dose-effect relationships, regional targets and sex selectivity. Neuropsychopharmacology 31: 12-35.

Lam F, Elliott J, Jones JS, Katz M, Knuppel RA, Morrison J et al (1998). Clinical issues surrounding the use of terbutaline sulfate for preterm labor. Obstet Gynecol Survey 53: S85-S95.

Maccari S, Darnaudery M, Morley-Fletcher S, Zuena AR, Cinque C, Van Reeth O (2003). Prenatal stress and long-term consequences: implications of glucocorticoid hormones. Neurosci Biobehav Rev 27: 119-127.

Matthews SG (2000). Antenatal glucocorticoids and programming of the developing CNS. Pediatr Res 47: 291-300.

Matthews SG, Owen D, Banjanin S, Andrews MH (2002). Glucocorticoids, hypothalamo-pituitary-adrenal (HPA) development, and life after birth. Endocr Res 28: 709-718.

McEwen BS (1992). Steroid hormones: effect on brain development and function. Hormone Res 37: 1-10.

Meaney MJ, Diorio J, Francis D, Widdowson J, LaPlante P, Caldji C et al (1996). Early environmental regulation of forebrain glucocorticoid receptor gene expression: implications for adrenocortical responses to stress. Dev Neurosci 18: 49-72.

Muneoka K, Mikuni M, Ogawa T, Kitera K, Kamei K, Takigawa M et al (1997). Prenatal dexamethasone exposure alters brain monoamine metabolism and adrenocortical response in rat offspring. Am J Physiol 42: R1669-R1675.

Nemeroff CB (1998). The neurobiology of depression. Sci Am 278: $42-49$.

Newnham JP (2001). Is prenatal glucocorticoid administration another origin of adult disease? Clin Exp Pharmacol Physiol 28: 957-961.

Nyirenda MJ, Welberg LA, Seckl JR (2001). Programming hyperglycaemia in the rat through prenatal exposure to glucocorticoids: fetal effect or maternal influence? J Endocrinol 170: $653-660$.

Raff H (2004). Neonatal dexamethasone therapy: short- and longterm consequences. Trends Endocrinol Metab 15: 351-352.

Rhodes MC, Seidler FJ, Abdel-Rahman A, Tate CA, Nyska A, Rincavage HL et al (2004). Terbutaline is a developmental neurotoxicant: effects on neuroproteins and morphology in cerebellum, hippocampus and somatosensory cortex. J Pharmacol Exp Ther 308: 529-537.

Rieger M, Pirke KM, Buske-Kirschbaum A, Wurmser H, Papousek M, Hellhammer DH (2004). Influence of stress during pregnancy on HPA activity and neonatal behavior. Ann NY Acad Sci 1032: 228-230.

Rodier PM (1988). Structural-functional relationships in experimentally induced brain damage. Prog Brain Res 73: 335-348.

Seckl JR (2001). Glucocorticoid programming of the fetus: adult phenotypes and molecular mechanisms. Mol Cell Endocrinol 185: $61-71$.

Seckl JR (2004). Prenatal glucocorticoids and long-term programming. Eur J Endocrinol 151: U49-U62.

Shahak H, Slotkin TA, Yanai J (2003). Alterations in PKC $\gamma$ in the mouse hippocampus after prenatal exposure to heroin: a link from cell signaling to behavioral outcome. Dev Brain Res 140: 117-125.

Shinwell ES, Karplus M, Reich D, Weintraub Z, Blazer S, Bader D et al (2000). Early postnatal dexamethasone treatment and 
increased incidence of cerebral palsy. Arch Dis Child 83: F177-F181.

Slotkin TA, Auman JT, Seidler FJ (2003). Ontogenesis of $\beta$-adrenoceptor signaling: implications for perinatal physiology and for fetal effects of tocolytic drugs. J Pharmacol Exp Ther 306: $1-7$.

Slotkin TA, Lappi SE, McCook EC, Tayyeb MI, Eylers JP, Seidler FJ (1992). Glucocorticoids and the development of neuronal function: effects of prenatal dexamethasone exposure on central noradrenergic activity. Biol Neonate 61: 326-336.

Slotkin TA, Lappi SE, Tayyeb MI, Seidler FJ (1991). Dosedependent glucocorticoid effects on noradrenergic synaptogenesis in rat brain: ontogeny of $\left[{ }^{3} \mathrm{H}\right]$ desmethylimipramine binding sites after fetal exposure to dexamethasone. Res Comm Chem Pathol Pharmacol 73: 3-19.

Slotkin TA, Seidler FJ, Ali SF (2000). Cellular determinants of reduced adaptability of the aging brain: neurotransmitter utilization and cell signaling responses after MDMA lesions. Brain Res 879: 163-173.

Song C (2000). The interaction between cytokines and neurotransmitters in depression and stress: possible mechanism of antidepressant treatments. Hum Psychopharmacol 15: 199-211.

Steingart RA, Barg J, Maslaton J, Nesher M, Yanai J (1998). Preand postsynaptic alterations in the septohippocampal cholinergic innervations after prenatal exposure to drugs. Brain Res Bull 46: 203-209.

Stokes PE, Maas JW, Davis JM, Koslow SH, Casper RC, Stoll PM (1987). Biogenic amine and metabolite levels in depressed patients with high versus normal hypothalamic-pituitaryadrenocortical activity. Am J Psychiatr 144: 868-872.

Trautman PD, Meyer-Bahlburg HFL, Postelnek J, New MI (1995). Effects of early prenatal dexamethasone on the cognitive and behavioral development of young children: results of a pilot study. Psychoneuroendocrinology 20: 439-449.
Vatury O, Barg J, Slotkin TA, Yanai J (2004). Altered localization of choline transporter sites in the mouse hippocampus after prenatal heroin exposure. Brain Res Bull 53: 25-32.

Weinstock M (2001). Alterations induced by gestational stress in brain morphology and behaviour of the offspring. Prog Neurobiol 65: 427-451.

Welberg LAM, Seckl JR (2001). Prenatal stress, glucocorticoids and the programming of the brain. J Neuroendocrinol 13: 113-128.

Xu Z, Seidler FJ, Ali SF, Slikker W, Slotkin TA (2001). Fetal and adolescent nicotine administration: effects on CNS serotonergic systems. Brain Res 914: 166-178.

Yanai J, Beer A, Huleihel R, Izrael M, Katz S, Levi Y et al (2004). Convergent effects on cell signaling mechanisms mediate the actions of different neurobehavioral teratogens: alterations in cholinergic regulation of $\mathrm{PKC}$ in chick and avian models. Ann NY Acad Sci 1025: 595-601.

Yatham LN, Liddle PF, Dennie J, Shiah IS, Adam MJ, Lane CJ et al (1999). Decrease in brain serotonin-2 receptor binding in patients with major depression following desipramine treatment: a positron emission tomography study with fluorine-18-labeled setoperone. Arch Gen Psychiatr 56: 705-711.

Yatham LN, Liddle PF, Shiah IS, Scarrow G, Lam RW, Adam MJ et al (2000). Brain serotonin-2 receptors in major depression: a positron emission tomography study. Arch Gen Psychiatr 57: 850-858.

Yeh TF, Lin YJ, Lin HC, Huang CC, Hsieh WS, Lin CH et al (2004). Outcomes at school age after postnatal dexamethasone therapy for lung disease of prematurity. $N$ Engl J Med 350: 1304-1313.

Young AH (1994). Glucocorticoids, serotonin and mood. $\mathrm{Br} J$ Psychiatr 165: 271-272.

Zahalka EA, Seidler FJ, Slotkin TA (1993). Dexamethasone treatment in utero enhances neonatal cholinergic nerve terminal development in rat brain. Res Comm Chem Pathol Pharmacol 81: 191-198. 